\title{
Avaliação de Impacto do Ciclo de Vida: revisão dos principais métodos
}

\author{
Natalia Crespo Mendes ${ }^{\text {a*}}$, Cristiane Bueno ${ }^{\mathrm{a}}$, Aldo Roberto Ometto ${ }^{\mathrm{a}}$ \\ a*Universidade de São Paulo, São Carlos, SP, Brasil, cm.natalia@gmail.com
}

\begin{abstract}
Resumo
Avaliação de Impacto do Ciclo de Vida (AICV) é a terceira fase da Avaliação do Ciclo de Vida (ACV) e tem como finalidade avaliar a significância ambiental dos resultados do inventário por meio de modelos e fatores de caracterização contidos nos métodos de AICV. Nesse contexto, este trabalho tem como objetivo identificar os principais métodos de AICV e descrever suas características. Por meio de uma revisão da literatura foram identificados 13 métodos de AICV, desenvolvidos majoritariamente em países da Europa e utilizados em todo o mundo, inclusive no Brasil. Dentre esses métodos foram reconhecidos aqueles que apresentam escopo de aplicação global, sendo recomendados para uso no Brasil. Cada método de AICV avalia as diferentes categorias de impacto por meio de uma série de modelos de caracterização, assim, concluiu-se ser necessário analisarem-se os procedimentos de cálculos utilizados por cada modelo, a fim de fornecer subsídios para aplicação desses métodos e modelos nas diferentes regiões do mundo.
\end{abstract}

Palavras-chave

Avaliação de Impacto do Ciclo de Vida. Métodos de Avaliação de Impacto do Ciclo de Vida.

\section{Introdução}

Desenvolvimento sustentável é aquele que visa atender as necessidades atuais sem que a possibilidade de as gerações futuras atenderem as delas seja comprometida (Organização das Nações Unidas, 2012). Além do desempenho técnico e dos custos, questões ambientais e sociais devem ser incorporadas à sociedade, a fim de se criarem negócios mais sustentáveis.

Nesse contexto, visando a qualidade ambiental de toda a cadeia de suprimentos, surge a gestão do ciclo de vida de produtos sustentáveis.

A Gestão do Ciclo de Vida (GCV) ou Life Cycle Management (LCM) é um sistema de gestão de produtos com o objetivo de minimizar encargos ambientais e socioeconômicos associados ao produto durante seu ciclo de vida (United Nations Environment Programme, 2007).

Diante dessa visão de ciclo de vida, umas das principais práticas aplicadas no desenvolvimento de produtos é a Avaliação do Ciclo de Vida (ACV).
ACV é a compilação e a avaliação das entradas, das saídas e dos potenciais impactos ambientais de um sistema de produto ao longo de seu ciclo de vida (Associação Brasileira de Normas Técnicas, 2009a, b), ela é composta pelas quatro fases apresentadas na Figura 1.

Na primeira fase ocorre a definição dos objetivos e do escopo do estudo. Em seguida há uma análise do inventário, que envolve a coleta dos dados necessários para o alcance dos objetivos do estudo em questão. A terceira fase, foco deste trabalho, refere-se à avaliação de impacto dos resultados do inventário, visando ao melhor entendimento de sua significância ambiental. E a quarta fase é de interpretação de todos os resultados em conjunto, com a finalidade de fornecer conclusões e recomendações para as partes interessadas.

Ao realizar um estudo de ACV e conhecer os impactos causados ao longo do ciclo de vida do produto, as empresas podem controlar impactos 


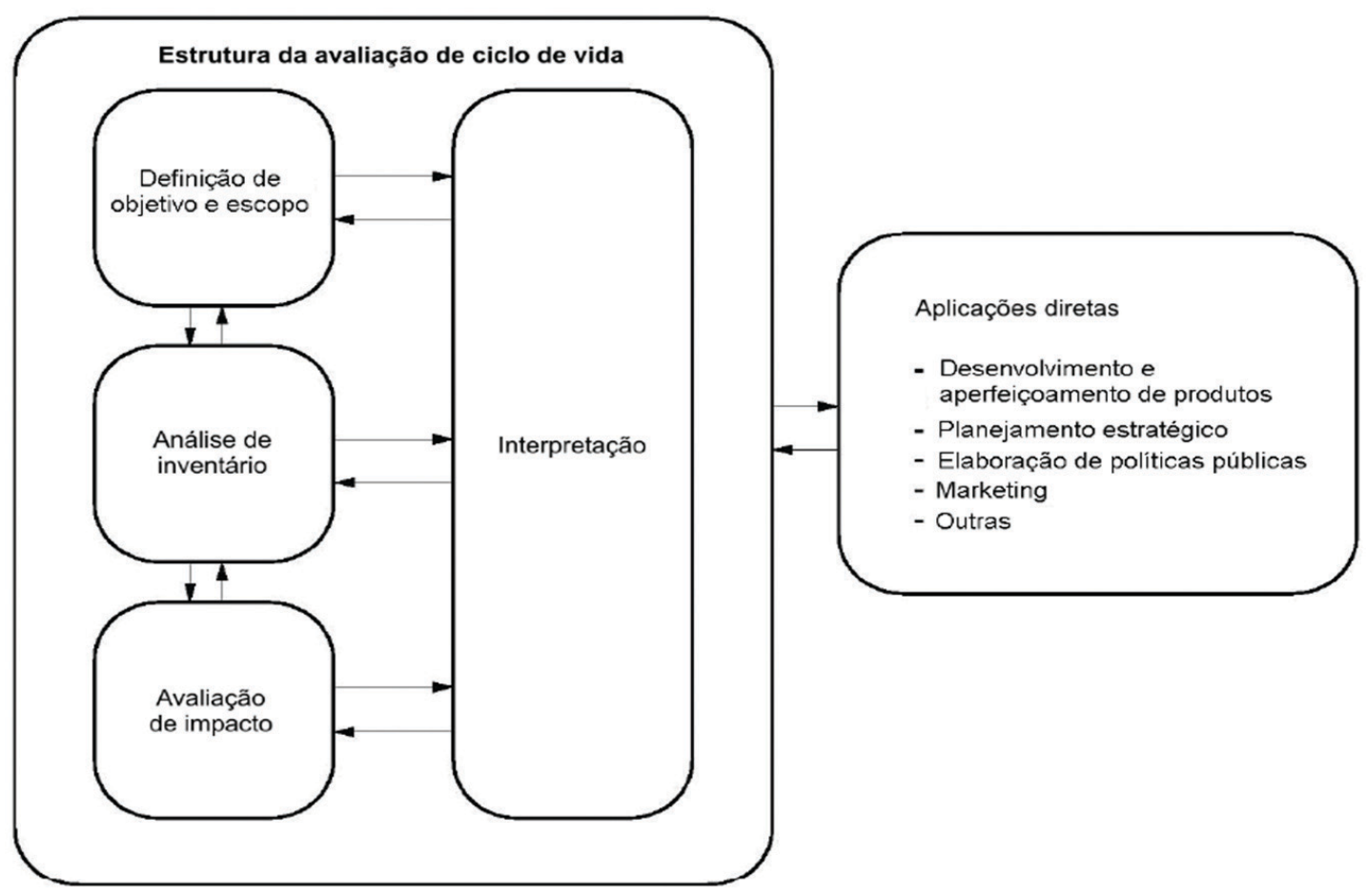

Figura 1. Fases de uma ACV. Fonte: Associação Brasileira de Normas Técnicas - ABNT (2009a).

ambientais negativos e introduzir melhorias em seus processos produtivos.

A ACV ainda é uma disciplina recente, desenvolvida principalmente a partir de meados da década de 1980 (Finnveden et al., 2009). Quanto à sua evolução e maturidade, Klöpffer (2006) afirma que a ACV tornou-se uma metodologia amplamente utilizada devido à sua forma integrada de tratar temas como estrutura, avaliação de impacto e qualidade dos dados. Organismos de normalização, como a 1SO, têm se abstido da padronização de escolhas metodológicas mais detalhadas, no entanto existem atualmente atividades internacionais que visam a elaboração de tais recomendações, as quais incluem modelos e fatores de caracterização para substâncias consideradas importantes (Finnveden et al., 2009).

Quando a ACV é utilizada para suporte à tomada de decisão, tal como em qualquer outra ferramenta, a incerteza dos resultados pode ser uma parte importante da informação. No âmbito da $1 S 0$ 14040, as questões relacionadas à incerteza são mencionadas como parte das fases de Avaliação de Impacto e de Análise de Inventário de Ciclo de Vida mas, de forma mais proeminente, como uma parte da fase de Interpretação, nenhuma indicação mais concreta para seus procedimentos de mensuração é fornecida. Essa questão está sendo abordada por diversas iniciativas em curso, as quais complementam as informações disponíveis na $\mathrm{ISO}$ e fornecem recomendações mais explícitas (Finnveden et al., 2009).

A fim de inserir e tornar efetiva a ACV como prática de apoio à sustentabilidade ambiental no Brasil e, dessa forma, apoiar o desenvolvimento sustentável e a competitividade ambiental da produção industrial brasileira, além de promover o acesso aos mercados interno e externo, foi aprovado pelo Conmetro o Programa Brasileiro de Avaliação de Ciclo de Vida (PBACV) (Brasil, 2010).

O PBACV aborda os seguintes temas estratégicos: Inventários do Ciclo de Vida, Avaliação de Impactos do Ciclo de Vida, Difusão e Implementação da ACV e Formação e Capacitação em ICV e ACV. A Tabela 1 apresenta o estágio futuro que se quer alcançar e as ações estratégicas que possibilitarão alcançar o estágio pretendido para o tema Avaliação de Impactos do Ciclo de Vida, de acordo com a Resolução n. 04/2010 (Brasil, 2010).

Nesse contexto, este trabalho vai ao encontro das propostas do PBACV no que se refere à temática Avaliação de Impacto do Ciclo de Vida e tem como objetivo identificar os principais métodos de AICV existentes e descrever suas características. Assim, pretende-se formar uma base para que a segunda ação estratégica referente aos métodos de AICV, mostrada na Tabela 1, possa ser futuramente realizada, possibilitando o desenvolvimento de procedimentos 
Tabela 1. Metas e ações estratégicas do PBACV para a Avaliação de Impacto do Ciclo de Vida.

\begin{tabular}{|c|c|c|}
\hline & Estágio a ser alcançado & Ações estratégicas \\
\hline \multirow{2}{*}{$\begin{array}{l}\text { Categoria de Impacto } \\
\text { do Ciclo de Vida }\end{array}$} & \multirow{2}{*}{$\begin{array}{l}\text { Categorias de impacto do ciclo de vida } \\
\text { para o Brasil definidas }\end{array}$} & - Pesquisar as categorias de impacto relevantes para a realidade brasileira \\
\hline & & - Definir as categorias de impacto relevantes para a realidade brasileira \\
\hline \multirow{2}{*}{$\begin{array}{l}\text { Modelos de } \\
\text { caracterização }\end{array}$} & Dados necessários definidos & - Identificar os dados necessários \\
\hline & $\begin{array}{l}\text { Dados necessários atualizados e } \\
\text { disponíveis }\end{array}$ & - Coletar, atualizar e disponibilizar os dados \\
\hline \multirow{2}{*}{ Métodos de AlCV } & \multirow{2}{*}{$\begin{array}{l}\text { Ter um método validado de AICV } \\
\text { aplicável no Brasil }\end{array}$} & - ldentificar os métodos de AICV existentes \\
\hline & & - Realizar adequações para estabelecer o método de AICV para o Brasil \\
\hline
\end{tabular}

metodológicos que sejam capazes de adequar os métodos existentes, de acordo com as características regionais do Brasil.

\section{Metodologia}

0 procedimento metodológico utilizado foi a revisão bibliográfica dos principais métodos de AICV. Foi realizado um levantamento na base de dados Web of Knowledge utilizando os seguintes strings de pesquisa: Life Cycle Impact Assessment (LCIA) AND methods; LCIA AND methodologies. A partir da análise das publicações sobre AICV foi possível identificar os métodos mais utilizados e citados em artigos disponíveis em bancos de dados internacionais.

Na revisão bibliográfica foram encontrados artigos que citavam também a publicação do International Reference Life Cycle Data System (ILCD) Handbook - Analysis of existing Environmental Impact Assessment Methodologies for use in Life Cycle Assessment - Background Document (Joint Research Centre, 2010) e documentos publicados pela UNEP referentes à fase de Avaliação de Impacto do Ciclo de Vida do Programa Iniciativa do Ciclo de Vida (United Nations Environment Programme, 2010), os quais foram utilizados como material complementar durante o desenvolvimento deste estudo.

A análise comparativa dos métodos de AICV identificados, com base na revisão bibliográfica, foi feita a partir das seguintes categorias de comparação:

- Local de origem - Indicação do país e/ou instituição de origem do método abordado.

- Nível de avaliação do impacto - Atribuição de níveis de avaliação do impacto a cada método, de acordo com os níveis definidos a seguir:

Midpoint - A caracterização usa indicadores localizados ao longo do mecanismo ambiental antes de chegar ao ponto final da categoria. Entende-se como mecanismo ambiental o sistema de processos físicos, químicos e biológicos para uma dada categoria de impacto, vinculando os resultados da análise do inventário do ciclo de vida aos indicadores de categoria e aos pontos finais da categoria (Associação Brasileira de Normas Técnicas, 2009a). Enquanto ponto final da categoria é o atributo ou aspecto do ambiente natural, saúde humana ou recursos que identifica uma questão ambiental merecedora de atenção (Associação Brasileira de Normas Técnicas, 2009a);

Endpoint - A caracterização considera todo o mecanismo ambiental até o seu ponto final, ou seja, refere-se a um dano específico relacionado com a área mais ampla de proteção, que pode ser saúde humana, ambiente natural ou recursos naturais. Sendo a área de proteção um conjunto de pontos finais da categoria de valor reconhecido pela sociedade, a saber, saúde humana, recursos naturais, ambiente natural e, às vezes, ambiente antrópico (Joint Research Centre, 2011; Guinée, 2002).

Combinado - Considera as vantagens das abordagens midpoint e endpoint.

- Categorias de impacto - Apresentação de todas as categorias de impacto avaliadas pelo método. As categorias de impacto avaliadas pela maioria dos métodos de AICV são chamadas neste trabalho de categorias de impacto tradicionais. As demais categorias abordadas são chamadas neste trabalho de categorias de impacto diferenciadas.

- Abrangência de aplicação - Determinação da abrangência do escopo regional de aplicação de cada método, classificando-a para cada categoria de impacto de acordo com os níveis apresentados a seguir:

Global;

Continental, nesse caso o nome do continente abordado é indicado;

Nacional, nesse caso o nome do país abordado é indicado.

0 conjunto de dados classificados com base nas categorias de comparação descritas nos itens acima foi examinado de modo a estabelecer semelhanças e particularidades entre os métodos de AICV. Dessa forma foi possível fornecer subsídios para a aplicação dos métodos de AICV no Brasil adotando como critério a abrangência de aplicação global dos métodos analisados. 


\section{Resultados}

A Tabela 2 apresenta os métodos de AICV abordados neste trabalho, que são descritos a seguir.

- CML 2002

0 CML 2002 ou Dutch Handbook on LCA é um manual holandês publicado em 2002 que apresenta diretrizes operacionais para a realização de um estudo passo a passo de ACV, com base nas normas ISO (Guinée, 2002). A versão revisada desse método é intitulada Handbook on Life Cycle Assessment: Operational Guide to the ISO Standards.

Esse método é baseado em uma abordagem midpoint e seus modelos de caracterização foram selecionados através de uma extensa revisão das metodologias existentes no mundo. 0 manual fornece fatores de caracterização para mais de 1.500 resultados diferentes de ICV, que podem ser encontrados em http://www.leidenuniv.nl/cml/ssp/projects/lca2/index. html (United Nations Environment Programme, 2010).

São abordadas as seguintes categorias de impacto: depleção de recursos abióticos, uso da terra, mudança climática, depleção de ozônio estratosférico, toxicidade humana, ecotoxicidade aquática de água doce, ecotoxicidade aquática marinha, ecotoxicidade terrestre, formação de foto-oxidantes, acidificação e eutrofização. Algumas categorias de impacto adicionais são abordadas, dependendo dos requisitos do estudo; entre elas estão: perda de função de suporte à vida, perda de biodiversidade, ecotoxicidade em água doce (sedimentos), ecotoxicidade marinha (sedimentos), impactos da radiação ionizante, mau cheiro do ar, barulho, calor residual, acidentes, letais, não letais, depleção de recursos bióticos, dessecação e mau cheiro da água (Joint Research Centre, 2010; Guinée, 2002).

0 método apresenta um escopo de aplicação global, exceto para as categorias de impacto acidificação e formação de foto-oxidantes, que apresentam escopo de aplicação direcionado para a Europa (Joint Research Centre, 2010).

O CML 2002 apresenta seis características particulares, são elas (Joint Research Centre, 2010):

- Fundamentos científicos explícitos que apoiam todas as escolhas importantes;

- Fatores de AICV alternativos fornecidos para análise de sensibilidade para cada categoria de impacto;

- Todos os fatores de AICV podem ser obtidos como planilhas, as quais são regularmente atualizadas;

- Distinção entre categorias de impacto básicas, específicas do estudo, e outras categorias de impacto;

- A maioria das categorias de impacto já foi descrita em artigos científicos;
Tabela 2. Métodos de AICV analisados.

\begin{tabular}{c}
\hline Métodos de AICV \\
\hline CML \\
Eco-indicator 99 \\
Ecological Scarcity \\
EDIP \\
EPS 2000 \\
Impact 2002+ \\
LIME \\
LUCAS \\
MEEuP \\
ReCiPe \\
TRACl \\
USEtox \\
IMPACT World+
\end{tabular}

- Princípios para AICV desenvolvidos juntamente com os princípios para outros elementos da metodologia de ACV (como unidade funcional, alocação etc.) de uma maneira consistente em relação à manipulação do tempo, espaço, não linearidades, mecanismos econômicos, sociais e tecnológicos etc.

\section{- Eco-indicator 99}

0 Eco-indicator 99 foi desenvolvido na Holanda como parte da Política Integrada de Produto do ministério holandês de Moradia, Planejamento Espacial e Ambiental (VROM). É um método endpoint, que visa simplificar a interpretação e ponderação dos resultados da ACV por meio do cálculo de pontuações únicas (eco indicadores). Entre as aplicações pretendidas está o uso por designers para a tomada de decisão (Joint Research Centre, 2010).

São abordadas três áreas de danos (Ministry OF Housing, Spatial Planning and the Environment, 2000):

Saúde humana (DALY) - Quantidade e duração das doenças e a perda de anos de vida por morte prematura devida a impactos ambientais.

Qualidade do ecossistema (\% de espécies que desapareceram) - Efeito na diversidade de espécies, especialmente para plantas e organismos menores.

Recursos (MJ de energia requerida) - Necessidade de geração de energia no futuro, para extrair recursos minerais e fósseis de menor qualidade. As perdas na agricultura e de recursos como areia e cascalho são relacionadas aos impactos do uso da terra.

Esse método apresenta escopo de aplicação global para as categorias de impacto mudança climática, depleção do ozônio e consumo de recursos minerais e fósseis, escopo de aplicação para o continente europeu para carcinogênicos, inaláveis orgânicos e inorgânicos, radiação ionizante e ecotoxicidade e escopo específico para a Holanda, para a acidificação e eutrofização, e para a Suíça, para o uso da terra (Joint Research Centre, 2010). 
0 Eco-indicator 99 sucedeu os métodos EPS 2000 e Eco-indicator 95 e serviu de ponto de partida para o desenvolvimento dos métodos LIME e Impact 2002 (Joint Research Centre, 2010).

Um diferencial dessa metodologia está relacionado à utilização de três perspectivas para criar três conjuntos consistentes de escolhas subjetivas a respeito, por exemplo, da perspectiva temporal aplicada, da importância da capacidade de gerenciamento, do papel do desenvolvimento tecnológico futuro e do nível necessário de provas de mecanismos de causa-efeito. Isso é feito através do uso consistente da mesma unidade de resultado para todas as categorias de impacto, resultando em danos para a saúde humana, ecossistemas ou recursos (Joint Research Centre, 2010).

\section{- Ecological Scarcity}

O Ecological Scarcity - também chamado Swiss Ecoscarcity ou Swiss Ecopoints - foi lançado em 1990, na Suiça (Ahbe et al., 1990), e atualizado nos anos 1997 e 2005 (United Nations Environment Programme, 2010), considerando os desenvolvimentos recentes na Suiça sobre efeitos ambientais, bem como a legislação e as metas ambientais europeias, na medida em que são relevantes para a Suiça, além das revisões das normas ISO (Frischknecht et al., 2006, 2009).

0 método tem como base o princípio "distância do alvo" (Frischknecht et al., 2009) ao invés de uma avaliação de impacto orientada ao dano (Frischknecht et al., 2006) e permite ponderação e agregação comparativa de várias intervenções ambientais pelo uso dos chamados ecofatores (Brand et al., 1998), expressos como ecopontos por unidade de emissão de poluentes ou extração de recursos (Frischknecht et al., 2009). Trata-se de um método receptivo à inclusão de novos problemas ambientais por meio do cálculo de um ecofator para a nova categoria de impacto (Brand et al., 1998).

As categorias de impacto abordadas são: mudança climática, depleção de ozônio, formação de oxidantes fotoquímicos, efeitos respiratórios, emissões para o ar, emissões para água de superfície, câncer proveniente de radionuclídeos emitidos no mar, emissões para águas subterrâneas, emissões para o solo, resíduos, consumo de água, consumo de areia/cascalho, fontes de energia primária, disruptores endócrinos e perda de biodiversidade por ocupação do solo (Joint Research Centre, 2010).

São particularidades do método a medição da escassez ecológica com a ajuda de fluxos reais de poluentes e recursos e de fluxos máximos permitidos, chamados críticos (United Nations Environment Programme, 2010), derivação direta das metas políticas (Frischknecht et al., 2006) e a possibilidade de uma avaliação compreensivel e transparente sobre uma base coerente (Brand et al., 1998).

\section{- EDIP 1997- EDIP 2003}

0 método EDIP 97 (Environmental Design of Industrial Products) foi desenvolvido na Dinamarca através do programa Danish EDIP, que representa a Universidade Técnica da Dinamarca (DTU), indústrias dinamarquesas e a Agência de Proteção Ambiental dinamarquesa, e foi financiado pelo Ministério do Meio Ambiente da Dinamarca (Wenzel et al., 1997).

A versão sucessora, EDIP 2003, inclui a avaliação de exposição com base em informações regionais de AICV de categorias de impacto de emissões não globais (Joint Research Centre, 2010).

Trata-se de um método midpoint desenvolvido para apoiar análises ambientais durante o desenvolvimento de produtos industriais e fornecer fatores de caracterização espacialmente diferenciados.

As categorias de impacto avaliadas pelo EDIP 97 são: aquecimento global, depleção de ozônio, acidificação, enriquecimento de nutrientes, formação de ozônio fotoquímico, toxicidade humana, ecotoxicidade, consumo de recursos e ambiente de trabalho (Hauschild $\&$ Wenzel, 1998). Nesse caso, o escopo de aplicação é global para todas as categorias (Joint Research Centre, 2010) e a modelagem de destino e efeito é baseada na seleção de propriedades químicas e físicas (Hauschild et al., 2008).

O EDIP 2003 contempla aquecimento global, depleção de ozônio, acidificação, eutrofização terrestre, eutrofização aquática, formação de ozônio fotoquímico, toxicidade humana, ecotoxicidade e barulho. Apresenta escopo de aplicação global para aquecimento global e depleção de ozônio, sendo direcionado para a Europa para as demais categorias (Joint Research Centre, 2010). Sua principal inovação, em relação à versão de 1997 , reside na tentativa consistente de incluir a modelagem de dispersão da substância e o aumento da exposição subsequente através da inclusão de uma parte maior da cadeia de causalidade e da diferenciação espacial em relação à emissão e ao meio receptor (Hauschild \& Potting, 2005).

Como particularidades, o EDIP 97 apresenta fatores de caracterização para todos os compostos orgânicos voláteis de origem petroquímica, no que diz respeito à categoria de impacto aquecimento global; fatores de caracterização para depleção de ozônio com horizontes de tempo mais curtos ( 5 a 20 anos); avaliação diferenciada do ambiente de trabalho; e revisão externa por pares de todos os modelos de caracterização (Joint Research Centre, 2010). Já o EDIP 2003 possui fatores de caracterização locais para mais de 40 regiões europeias e fatores de 
caracterização locais genéricos compatíveis baseados na média europeia de ponderação (Joint Research Centre, 2010).

\section{- EPS 2000}

0 Environmental Priority Strategies in product development - EPS 2000 foi desenvolvido na Suécia, na Universidade de Tecnologia Chalmers, com a participação das indústrias (Steen, 1999a, b). Os princípios e a metodologia são baseados em versões anteriores, em particular a de 1996, no entanto a descrição é mais detalhada e adotam-se termos padrão da ISO (Steen, 1999a, b).

0 EPS 2000 é um método de avaliação endpoint criado para ajudar designers e desenvolvedores de produtos durante a escolha entre dois conceitos de produto e os indicadores de categoria são escolhidos para esse fim, sendo adequados para atribuir valores de categorias de impacto (Joint Research Centre, 2010; Steen, 1999a; United Nations Environment Programme, 2010).

Os indicadores de categoria são selecionados para representar impactos ambientais em qualquer uma das cinco áreas de proteção consideradas: saúde humana, capacidade de produção dos ecossistemas, recursos abióticos, biodiversidade e ações culturais e recreativas (Joint Research Centre, 2010; Steen, 1999a; United Nations Environment Programme, 2010).

São abordadas as categorias saúde humana, expectativa de vida, morbidade grave e sofrimento, morbidade, incômodo grave, incômodo, ambiente natural, capacidade de produção agrícola, capacidade de produção de madeira, capacidade de produção de peixe e carne, capacidade de cátions de base, capacidade de produção de água potável, parcela de extinção de espécies, consumo de recursos naturais, esgotamento de reservas de elementos, esgotamento de reservas fósseis (gás), esgotamento de reservas fósseis (petróleo), esgotamento de reservas fósseis (carvão) e esgotamento de recursos minerais (Joint Research Centre, 2010; Steen, 1999b).

Esse método abrange aproximadamente 200 substâncias e todos os efeitos são calculados por substância, conferindo a ele maior precisão. Também contempla emissões de aeronaves em altas altitudes (Joint Research Centre, 2010).

Apresenta escopo de aplicação global e somente para a categoria de impacto perda de biodiversidade o modelo utilizado é específico para a Suécia (Joint Research Centre, 2010).

As principais particularidades dessa metodologia são a consistência da abordagem média, onde os níveis médios de danos observados estão relacionados com o nível estressor a partir do qual os fatores de impacto são estimados, o que resulta em estimativas; o mercado atual é o cenário padrão para resultados tecnológicos do futuro, com um fator de dano alto para o esgotamento de recursos, e todos os efeitos são calculados por substância, o que the confere precisão maior do que a utilização do princípio guarda-chuva (Joint Research Centre, 2010).

\section{- IMPACT 2002+}

0 Impact Assessment of Chemical Toxics, IMPACT 2002+, é um método suíço que propõe a implementação da avaliação combinada midpoint/ endpoint ligando todos os tipos de resultados do inventário através de 14 categorias midpoint e quatro endpoint (Jolliet et al., 2003).

Esse método tem escopo de aplicação válido para a Europa e as categorias de impacto midpoint abordadas são: toxicidade humana, efeitos respiratórios, radiação ionizante, depleção de ozônio, formação de ozônio fotoquímico, ecotoxicidade aquática, ecotoxicidade terrestre, acidificação aquática, eutrofização aquática, acidificação e eutrofização terrestre, ocupação do solo, aquecimento global, uso de energia renovável e extração mineral. Enquanto as categorias endpoint são: saúde humana, qualidade do ecossistema, mudança climática e recursos (Joint Research Centre, 2010).

0 método Impact 2002+ fornece fatores de caracterização para quase 1.500 substâncias, as quais podem ser encontrados em http://www.epfl. ch/impact (United Nations Environment Programme, 2010). Essa metodologia apresenta novos conceitos e métodos de avaliação comparativa de toxicidade humana e efeitos de ecotoxicidade. Para a categoria consumo de recursos, o conceito de energia excedente define-se somando-se energia primária e excedente para os combustíveis fósseis e desenvolvimentos têm sido realizados sobre a exposição ao ar interior de ambientes fechados e os impactos diretos de pesticidas (Joint Research Centre, 2010).

\section{- LIME}

0 Life-cycle Impact assessment Method based on Endpoint modeling, LIME, foi lançado em 2003 pelo Instituto Nacional de Ciência e Tecnologia Industrial Avançada (AIST) em cooperação com o Comitê de Estudo de Avaliação de Impacto do Projeto $\mathrm{ACV}$, visando quantificar os impactos ambientais associados às cargas ambientais no Japão com a maior precisão possível e com grau elevado de transparência (Itsubo et al., 2004). A documentação do método LIME ainda não foi completamente traduzida, porém alguns artigos científicos estão disponíveis (Joint Research Centre, 2010). 0 fato de as descrições do método estarem escritas em sua maioria em japonês é considerado uma limitação para o seu estudo.

0 método é desenvolvido para as condições naturais e humanas japonesas e aborda danos 
associados ao ambiente artificial, a fim de refletir as condições ambientais do Japão e atender aos objetivos da ACV (Joint Research Centre, 2010; ltsubo et al., 2004). Trata-se de um método com escopo de aplicação global para aquecimento global e destruição da camada de ozônio e específico para o Japão nas demais categorias de impacto (Joint Research Centre, 2010).

As categorias midpoint abordadas são: poluição do ar urbano, aquecimento global, depleção da camada de ozônio, toxicidade humana, ecotoxicidade, acidificação, eutrofização, formação de oxidantes fotoquímicos, uso da terra, consumo de minerais, consumo de energia, consumo de recursos bióticos, poluição do ar inteior de ambientes fechados, geração de ruídos e geração de resíduos. Dentre as categorias endpoint avaliadas estão: estresse térmico, malária, doenças infecciosas, fome e desastres naturais, catarata, câncer de pele, outro câncer, deficiência respiratória, biodiversidade (terrestre), biodiversidade (aquática), plantas, bentos, pesca, colheita, materiais, recursos minerais e recursos energéticos (Joint Research Centre, 2010).

As categorias citadas são sumarizadas em quatro tipos de danos: saúde humana, bem-estar social, biodiversidade e produção primária, caracterizando o LIME como um método com nível de avaliação combinado, que correlaciona categorias de impactos a quatro áreas de proteção (1tsubo \& Inaba, 2003).

A abordagem de danos associados ao ambiente construído é um diferencial dessa metodologia. Além disso, a monetização é usada para avaliação e também pode ser usada com painel de ponderação, mas é a modelagem sistemática do ponto médio até o ponto final que confere força à metodologia e o modelo proposto deve ser sistematicamente considerado por essa função.

\section{- LUCAS}

O LUCAS (LCIA method Used for a CAnadianSpecific context) foi desenvolvido em 2005 pelo Centro de Pesquisa Interuniversitário para o Ciclo de Vida de Produtos, Processos e Serviços (CIRAIG) da Escola Politécnica de Montreal, no Canadá, com o objetivo de fornecer uma metodologia adaptada ao contexto canadense (Joint Research Centre, 2010). Esse método segue as recomendações da SETAC durante as escolhas dos requisitos para adaptação de modelos de caracterização de métodos já existentes. Inicialmente foram selecionados modelos de caracterização para dez categorias de impacto que apresentam abordagem midpoint. São considerados os modelos utilizados pelos métodos EDIP 2003, Impact 2002+, LIME e TRACl, por serem os métodos que incluíam as especificidades locais em seus fatores de caracterização até a data de desenvolvimento do modelo LUCAS (Toffoletto et al., 2007).

Os fatores de caracterização foram desenvolvidos para serem local-dependentes. Uma divisão do Canadá em 15 ecozonas considerando clima, relevo, solo, fauna, flora e atividades humanas distintas de cada ecozona foi feita de modo que os dados necessários para a modelagem estivessem disponíveis (Toffoletto et al., 2007).

As categorias de impacto abordadas são: mudança climática, depleção de ozônio, acidificação, neblina fotoquímica, efeitos respiratórios, eutrofização aquática, eutrofização terrestre, ecotoxicidade (aquática e terrestre), toxicidade humana, uso da terra e destruição de recursos abióticos (Joint Research Centre, 2010). 0 LUCAS utiliza os modelos do método TRACl para as categorias de impacto acidificação e neblina fotoquímica, visto que Canadá e Estados Unidos compartilham regulamentos semelhantes para poluição atmosférica (Toffoletto et al., 2007).

A abrangência do escopo de aplicação é global para as categorias de impacto mudança climática e depleção de ozônio e específica para o Canadá para as demais categorias de impacto (Joint Research Centre, 2010). Trata-se de um método de abordagem midpoint que, eventualmente, poderá ser desenvolvido para o nível endpoint, já que as categorias ecotoxicidade e toxicidade são baseadas no método lmpact 2002+e fatores de caracterização midpoint e endpoint estão disponiveis (Toffoletto et al., 2007).

Algumas características diferenciais da metodologia são a definição espacial para as categorias de impacto regional com foco no Canadá (acidificação, ozônio fotoquímico, eutrofização aquática, eutrofização terrestre, ecotoxicidade aquática e terrestre e toxicidade humana) e o desenvolvimento de fatores de vulnerabilidade para introduzir especificidades locais de impactos regionais para a modelagem de efeitos da acidificação e da eutrofização (aquática e terrestre).

\section{- MEEuP}

0 MEEuP (Methodology study for Eco-design of Energy-using Products) foi desenvolvido em nome da Comissão Europeia para avaliar quais e em que medida diversos produtos consumidores de energia cumprem determinados critérios que os tornam elegiveis para rotulagem CE (sob aplicação de medidas previstas na Diretiva 2005/32/CE) adotando-se uma abordagem de ciclo de vida. 0 método inclui, além de dados de inventário e parâmetros técnicos para produtos elétricos, fatores específicos de avaliação de impacto com uma abordagem única, destinando-se também a apoiar o ecodesign em geral (Joint Research Centre, 2010; Kemna et al., 2005). 
Seu escopo de aplicação é válido para a União Europeia e as categorias de impacto abordadas são: consumo total de energia bruta, consumo de eletricidade, consumo de água (processos), consumo de água para resfriamento, resíduos sólidos perigosos, resíduos não perigosos, aquecimento global, destruição do ozônio estratosférico, acidificação, emissão de poluentes orgânicos persistentes, emissão de compostos orgânicos voláteis, emissão de metais pesados (ar), emissão de metais pesados (água), toxicidade humana, formação de partículas e eutrofização aquática.

Aproximadamente 50 substâncias são consideradas, com fatores de caracterização para mais de uma categoria de impacto.

0 método diferencia-se por ser usado, principalmente por parte da União Europeia, para a avaliação de produtos que consomem energia e, portanto, ser baseado em diretivas comunitárias ou acordos internacionais, que são melhor aceitos pelos órgãos governamentais.

\section{- ReCiPe}

0 método ReCiPe é uma continuação dos métodos Eco-indicador 99 e CML 2000 que integra e harmoniza as abordagens midpoint e endpoint em uma estrutura comum e consistente. As categorias de impacto abordadas são: mudança climática, depleção de ozônio, acidificação terrestre, eutrofização aquática de água doce, eutrofização aquática marinha, toxicidade humana, formação de oxidantes fotoquímicos, formação de matéria particulada, ecotoxicidade terrestre, ecotoxicidade aquática de água doce, ecotoxicidade aquática marinha, radiação ionizante, uso do solo agrícola, uso do solo urbano, transformação de terra natural, esgotamento de recursos fósseis, esgotamento de recursos minerais e esgotamento de recursos de água doce (Joint Research Centre, 2010; Goedkoop et al., 2009).

Segundo De Schryver et al. (2009), os fatores de caracterização para aquecimento global foram adequados para comparar os impactos dos gases de efeito estufa com outros tipos de influência, tais como substâncias que causam acidificação e impactos respiratórios. Para a saúde humana, cinco diferentes efeitos sobre a saúde foram incluídos, como desnutrição e diarreia, ainda assim existem doenças relacionadas ao aquecimento global que não são consideradas nos cálculos devido a limitações relacionadas aos dados.

Para todas as categorias de emissão princípios e escolhas semelhantes são usados e todas as categorias de impacto da mesma área de proteção têm a mesma unidade de indicador. Os mesmos mecanismos ambientais são usados para cálculos midpoint e endpoint (Joint Research Centre, 2010).
Esse método tem escopo de aplicação global para as categorias de impacto mudança climática, destruição da camada de ozônio e consumo de recursos e escopo de aplicação válido para a Europa para as demais categorias de impacto.

\section{- TRACl}

0 TRACl (Tool for the Reduction and Assessment of Chemical and other environmental Impacts) é um método de avaliação do impacto elaborado pela Agência de Proteção Ambiental dos Estados Unidos (US-EPA) em 2003, originalmente projetado para uso na ACV, esperando-se também encontrar uma aplicação mais ampla na Prevenção da Poluição (P2) e em medidas de sustentabilidade para os Estados Unidos (Bare, 2002; Bare et al., 2003; United Nations Environment Programme, 2010).

Trata-se de um método midpoint que considera as condições ambientais dos Estados Unidos, como um todo ou por estados.

As categorias de impacto foram selecionadas com base em seu nível de concordância com a literatura existente nessa área, sua coerência com os regulamentos e políticas da EPA, seu estado atual de desenvolvimento e o valor nela reconhecido pela sociedade (Bare, 2002). São abordadas as seguintes categorias de impacto: depleção de ozônio, aquecimento global, formação de fumaça (smog), acidificação, eutrofização, saúde humana (carcinogênicos), saúde humana (não carcinogênicos), saúde humana (poluentes), ecotoxicidade e esgotamento de combustíveis fósseis (Joint Research Centre, 2010). Além das categorias já citadas, Bare et al. (2003) ainda acrescentam as categorias de uso da terra e uso da água.

0 método apresenta escopo de aplicação global para as categorias depleção de ozônio e aquecimento global, escopo de aplicação válido para a América do Norte para acidificação, eutrofização e formação de fumaça e escopo de aplicação válido para os Estados Unidos para as categorias relacionadas a saúde humana e ecotoxicidade (Joint Research Centre, 2010). De acordo com Bare et al. (2003), as categorias acidificação, eutrofização, formação de fumaça (smog), saúde humana (carcinogênicos, não carcinogênicos e poluentes) e uso da terra foram desenvolvidas utilizando-se os parâmetros norte-americanos para fazê-las mais aplicáveis à situação dos Estados Unidos, e algumas dessas categorias permitem uma resolução espacial a nível estadual ou inferior.

Aproximadamente 900 substâncias são abordadas na versão original do TRACl. Espera-se que a nova versão inclua aproximadamente 3.000 substâncias (Joint Research Centre, 2010).

Esse método é apoiado pela US-EPA e é especialmente relevante para as emissões que ocorrem 
como parte de ciclos de vida do produto nos Estados Unidos, possuindo fatores de caracterização regionais para a acidificação, eutrofização e formação de fumaça.

\section{- USEtox}

O USEtox é um método com nível de avaliação midpoint projetado para descrever destino, exposição e efeitos de produtos químicos, fornecendo fatores de caracterização recomendados para a toxicidade humana e ecotoxicidade de água doce na avaliação de impacto do ciclo de vida (Joint Research Centre, 2010; Huijbregts et al., 2010).

A escala continental é composta pelos seguintes compartimentos: ar urbano, ar rural, água doce, água do mar, solo natural e solo agrícola, enquanto a escala global abrange os compartimentos ar, água doce, oceanos, solo natural e solo agrícola (Huijbregts et al., 2010), ou seja, apresenta a mesma estrutura que a escala continental, mas sem o compartimento referente ao ar urbano (Rosenbaum et al., 2008).

No método USEtox são determinados fatores para impactos cancerígenos, não cancerígenos e impactos totais. Os dados para efeitos após inalação e exposição por via oral são determinados separadamente (Huijbregts et al., 2010).

De acordo com Huijbregts et al. (2010) e Rosenbaum et al. (2008), o fator de caracterização para toxicidade humana é expresso em unidades de tóxicos comparativas (CTU), proporcionando a estimativa do aumento da morbidade na população humana total por unidade de massa de um produto químico emitido (casos $/ \mathrm{kg}$ emitido), assumindo peso igual para cancerígenos e não cancerígenos devido à falta de conhecimentos mais precisos sobre essa questão. 0 fator de caracterização para a ecotoxicidade aquática também é expresso em CTU e fornece uma estimativa da fração potencialmente afetada (PAF) de espécies ao longo do tempo e de volume por unidade de massa de um produto químico emitido (PAF dia. $\mathrm{m}^{3} \cdot \mathrm{kg}^{-1}$ ).

Fatores de caracterização adicionais estão em desenvolvimento para avaliar de modo coerente o impacto de partículas primárias e secundárias, bem como das emissões para o ar no interior de ambientes fechados (Joint Research Centre, 2010).

Com o objetivo de dispor um conjunto de dados consistentes, computando o maior número possível de fatores de caracterização, foi criado um banco de dados de propriedades químicas. Esse banco de dados inclui propriedades físico-químicas, dados toxicológicos de animais obtidos em laboratório, como base para os de seres humanos, e dados ecotoxicológicos para organismos de água doce (Rosenbaum et al., 2008).

Aplicando-se o USEtox com um banco de dados bem referenciado são encontrados fatores de caracterização para 991 substâncias orgânicas (mais 260 fatores de caracterização provisórios) na categoria de impacto toxicidade humana e para 1.299 substâncias orgânicas (mais 1.247 fatores de caracterização provisórios) na categoria de impacto ecotoxicidade de água doce (Rosenbaum et al., 2008).

\section{- IMPACT World +}

0 método IMPACT World+ foi desenvolvido diante da necessidade de uma avaliação de impacto regionalizada cobrindo todas as regiões do mundo. Estão envolvidos nessa pesquisa especialistas do grupo de pesquisa CIRAIG, da Politécnica de Montreal (Canadá), Universidade de Michigan (Estados Unidos), Universidade de Ann Arbor (Estados Unidos), Quantis (Suíça), Universidade Técnica da Dinamarca - DTU (Dinamarca), Escola Politécnica de Lausanne - EPFL (Suiça) e Cycleco (França), além da Fundação Alcoa, a qual colabora com investimentos financeiros.

Os modelos de caracterização são uma atualização dos modelos existentes nos métodos Impact 2002+, EDIP e LUCAS, o que resultou em fatores de caracterização para diferentes resoluções geográficas, cada um com sua própria incerteza e variabilidade espacial associada (IMPACT World+, 2012).

A escala espacial considerada é definida em torno dos parâmetros de modelagem mais sensiveis e espacialmente variáveis, tais como bacias para impactos de uso da água ou biomas para impactos de uso da terra (IMPACT World+, 2012).

0 IMPACT World+ (2012) traz como principais diferenciais:

0 modelo USEtox para impactos tóxicos e os impactos do uso da água com fatores continentais específicos e alternativas especializadas consistentes.

Desenvolvimento de melhorias de modelagem para uso da terra, com a inclusão dos serviços dos ecossistemas; para acidificação, com uma modelagem melhor para destino atmosférico; para o uso de recursos, com a introdução de uma abordagem de extração-consumo-competição; para efeitos respiratórios, com novos fatores derivados de epidemias e a inclusão dos impactos de resíduos de pesticidas; e, finalmente, para a eutrofização, com um modelo mundial de resolução de $0,5 \times 0,5$ graus.

Para algumas categorias de impacto, os indicadores midpoint podem ser atribuídos a subcategorias, por exemplo, a categoria toxicidade humana é composta por substâncias não cancerígenas, cancerígenas, inorgânicos inaláveis e radiações ionizantes.

Enquanto os indicadores midpoint podem ser apresentados e interpretados separadamente, cada impacto midpoint também é modelado nas três áreas de proteção: saúde humana, qualidade dos ecossistemas e serviços e recursos ambientais. A 
última área de proteção inclui os impactos sobre a sociedade humana sem consequências diretas sobre a saúde, tais como o uso de recursos abióticos e a depreciação dos serviços dos ecossistemas.

São, portanto, abordadas as seguintes categorias de impacto: toxicidade humana, oxidação fotoquímica, depleção da camada de ozônio, aquecimento global, ecotoxicidade, acidificação, eutrofização, uso da água, uso da terra e uso de recursos.

\section{Análise comparativa entre os métodos de AICV e subsídios para a aplicação no Brasil}

A Tabela 3 refere-se ao local de origem de cada método. Os principais métodos de AICV foram desenvolvidos majoritariamente em países da Europa, é o caso do CML 2002, Eco-indicator 99, Ecological Scarcity, EDIP, EPS 2000, Impact 2002+, MEEuP e ReCiPe. LUCAS e TRACl têm origem em países da América do Norte e LIME é um método desenvolvido pelo Japão. Observa-se que os métodos mais recentes, USEtox e IMPACT World+, foram desenvolvidos por grupos de pesquisa que envolvem pesquisadores de todo o mundo, o que pode demonstrar uma tentativa de globalização quanto à aplicação desses métodos.

Verifica-se, assim, uma lacuna de métodos originados no Brasil, bem como na América do Sul, o que possivelmente implica na ausência de procedimentos de caracterização direcionados ao contexto brasileiro. Deve-se, portanto, incentivar as pesquisas nessa área do conhecimento e a participação de especialistas brasileiros em projetos de alcance global nesse tema.

A Tabela 4, baseada nas referências bibliográficas utilizadas neste artigo, apresenta uma relação de características dos métodos de AICV classificados de acordo com as categorias de comparação anteriormente estabelecidas na seção 2, Metodologia.

Com relação à primeira categoria de comparação apresentada na Tabela 4, nível de avaliação, é possível observar que as versões mais atuais dos métodos de AICV apresentam níveis de avaliação midpoint ou combinado. Isso se justifica pelo fato de as avaliações no nível endpoint apresentarem modelagem com complexidade e incertezas claramente maiores do que a modelagem midpoint (Hauschild et al., 2012).

Quanto às categorias de impacto abordadas pelos métodos de AICV, as consideradas neste trabalho como tradicionais são avaliadas por praticamente todos os métodos. Verifica-se também que métodos como Ecological Scarcity, EPS 2000 e LIME apresentam a maioria de suas categorias com abordagens diferenciadas, demonstrando que a temática das categorias presentes pode variar de acordo com cada método, como é também o caso do método USEtox, desenvolvido para avaliar especificamente impactos toxicológicos.

Deve-se destacar que a existência de métodos que abordem categorias mais específicas, além das tradicionais, representa possibilidade de desenvolvimento de modelos direcionados ao estudo de características particulares de cada região.

No que diz respeito ao escopo de aplicação, nota-se que a maioria dos métodos de AICV apresentados neste artigo foi criada considerando escopos regionais específicos, embora sejam aplicados em diferentes partes do mundo, incluindo-se o Brasil.

Por não existirem métodos desenvolvidos especificamente para o contexto brasileiro nem para a América do Sul, a partir dos resultados obtidos na Tabela 4 buscou-se fornecer subsídios para a aplicação, no Brasil, dos métodos de AICV disponíveis.

Tabela 3. Métodos de AICV e sua origem.

\begin{tabular}{ll}
\hline Método & Origem \\
\hline CML2002 & CML - Holanda \\
Eco-indicator 99 & Pré - Holanda \\
Ecological Scarcity & E2 + ESU-services - Suiça \\
EDIP97 - EDIP2003 & DTU - Dinamarca \\
EPS 2000 & IVL - Suécia \\
Impact 2002+ & EPFL - Suíça \\
LIME & AlST - Japão \\
LUCAS & CIRAlG - Canadá \\
MEEuP & VhK - Holanda \\
ReCiPe & RUN + PRé + CML + RIVM - Holanda \\
TRACl & US EPA - Estados Unidos \\
USEtox & Programa Iniciativa do Ciclo de Vida da UNEP - SETAC \\
IMPACT World + & CIRAlG, da Politécnica de Montreal (Canadá), Universidade de Michigan (Estados Unidos), Universidade de \\
& Ann Arbor (Estados Unidos), Quantis (Suíça), Universidade Técnica da Dinamarca - DTU (Dinamarca), Escola \\
\hline
\end{tabular}


Tabela 4. Principais métodos de AICV e suas características.

\begin{tabular}{|c|c|c|c|c|c|}
\hline Método & $\begin{array}{c}\text { Nivel de } \\
\text { avaliação de } \\
\text { impacto }\end{array}$ & Categorias de impacto tradicionais & $\begin{array}{l}\text { Abrangência de } \\
\text { aplicação }\end{array}$ & Categorias de impacto diferenciadas & $\begin{array}{l}\text { Abrangência } \\
\text { de aplicação }\end{array}$ \\
\hline \multirow{13}{*}{ 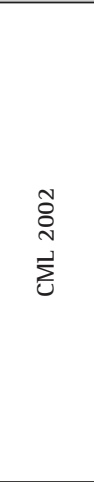 } & \multirow{13}{*}{ 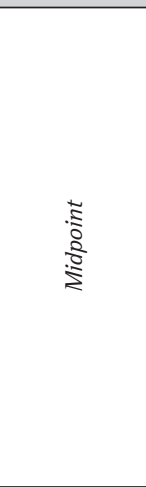 } & Depleção de recursos abióticos & Global & Perda de função de suporte à vida & Global \\
\hline & & Depleção de recursos bióticos & Global & Perda de biodiversidade & Global \\
\hline & & Uso da terra & Global & Ecotoxicidade em água doce (sedimentos) & Global \\
\hline & & Mudança climática & Global & Ecotoxicidade marinha (sedimentos) & Global \\
\hline & & Depleção do ozônio estratosférico & Global & Impactos da radiação ionizante & Global \\
\hline & & Toxicidade humana & Global & Mau cheiro do ar & Global \\
\hline & & Ecotoxicidade aquática (água doce) & Global & Barulho & Global \\
\hline & & Ecotoxicidade aquática (marinha) & Global & Calor residual & Global \\
\hline & & Ecotoxicidade terrestre & Global & Acidentes & Global \\
\hline & & Formação de foto-oxidantes & Europa & Letais & Global \\
\hline & & Acidificação & Europa & Não letais & Global \\
\hline & & Eutrofização & Global & Dessecação & Global \\
\hline & & & & Mau cheiro da água & Global \\
\hline \multirow{7}{*}{ 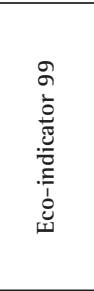 } & \multirow{7}{*}{ 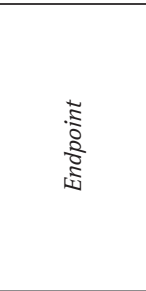 } & Mudança climática & Global & Carcinogênicos & Europa \\
\hline & & Depleção da camada de ozônio & Global & Inaláveis orgânicos & Europa \\
\hline & & $\begin{array}{l}\text { Acidificação e eutrofização } \\
\text { combinadas }\end{array}$ & Holanda & Inaláveis inorgânicos & Europa \\
\hline & & Ecotoxicidade & Europa & Radiação ionizante & Europa \\
\hline & & Uso da terra & Suiça & & \\
\hline & & Recursos minerais & Global & & \\
\hline & & Recursos fósseis & Global & & \\
\hline \multirow{9}{*}{ 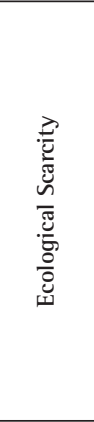 } & \multirow{9}{*}{ 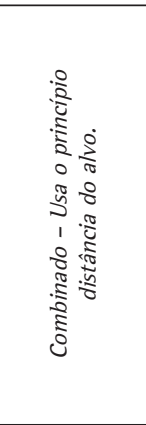 } & Mudança climática & Suiça & Efeitos respiratórios & Suiça \\
\hline & & Depleção de ozônio & Suiça & Emissões para o ar & Suiça \\
\hline & & $\begin{array}{l}\text { Formação de oxidantes } \\
\text { fotoquímicos }\end{array}$ & Suiça & Emissões para água de superfície & Suiça \\
\hline & & Consumo de água & Suiça & $\begin{array}{l}\text { Câncer proveniente de radionuclídeos } \\
\text { emitidos no mar }\end{array}$ & Suiça \\
\hline & & Consumo de areia/cascalho & Suiça & Emissões para águas subterrâneas & Suíça \\
\hline & & $\begin{array}{l}\text { Perda de biodiversidade por } \\
\text { ocupação do solo }\end{array}$ & Suíça & Emissões para o solo & Suiça \\
\hline & & & & Resíduos & Suiça \\
\hline & & & & Fontes de energia primária & Suiça \\
\hline & & & & Disruptores endócrinos & Suiça \\
\hline \multirow{8}{*}{ 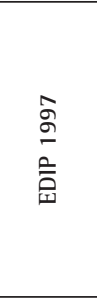 } & \multirow{8}{*}{ 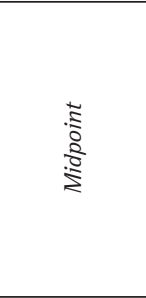 } & Aquecimento global & Global & Ambiente de trabalho & Global \\
\hline & & Depleção de ozônio & Global & & \\
\hline & & Acidificação & Global & & \\
\hline & & Enriquecimento de nutrientes & Global & & \\
\hline & & Formação de ozônio fotoquímico & Global & & \\
\hline & & Toxicidade humana & Global & & \\
\hline & & Ecotoxicidade & Global & & \\
\hline & & Consumo de recursos & Global & & \\
\hline \multirow{8}{*}{ 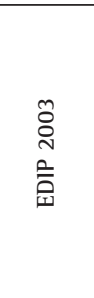 } & \multirow{8}{*}{ 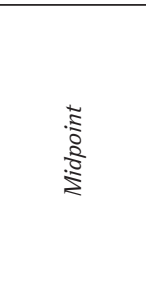 } & Aquecimento global & Global & Barulho & Europa \\
\hline & & Depleção de ozônio & Global & & \\
\hline & & Acidificação & Europa & & \\
\hline & & Eutrofização terrestre & Europa & & \\
\hline & & Eutrofização aquática & Europa & & \\
\hline & & Formação de ozônio fotoquímico & Europa & & \\
\hline & & Toxicidade humana & Europa & & \\
\hline & & Ecotoxicidade & Europa & & \\
\hline \multirow{5}{*}{$\begin{array}{l}\stackrel{8}{8} \\
\text { N } \\
\text { ָิ }\end{array}$} & \multirow{5}{*}{$\begin{array}{l}\tilde{\Xi} \\
\frac{\Xi}{0} \\
\frac{2}{2} \\
\text { î }\end{array}$} & Saúde humana & Global & Expectativa de vida & Global \\
\hline & & Consumo de recursos naturais & Global & Morbidade grave e sofrimento & Global \\
\hline & & $\begin{array}{l}\text { Esgotamento de reservas de } \\
\text { elementos }\end{array}$ & Global & Morbidade & Global \\
\hline & & $\begin{array}{l}\text { Esgotamento de reservas fósseis } \\
\text { (gás) }\end{array}$ & Global & Incômodo grave & Global \\
\hline & & $\begin{array}{l}\text { Esgotamento de reservas fósseis } \\
\text { (petróleo) }\end{array}$ & Global & Incômodo & Global \\
\hline
\end{tabular}


Mendes, N. C. et al.

Avaliação de Impacto do Ciclo de Vida: revisão dos principais métodos. Production, 26(1), 160-175, jan./mar. 2016

Tabela 4. Continuação...

\begin{tabular}{|c|c|c|c|c|c|}
\hline Método & $\begin{array}{l}\text { Nível de } \\
\text { avaliação de } \\
\text { impacto }\end{array}$ & Categorias de impacto tradicionais & $\begin{array}{l}\text { Abrangência de } \\
\text { aplicação }\end{array}$ & Categorias de impacto diferenciadas & $\begin{array}{l}\text { Abrangência } \\
\text { de aplicação }\end{array}$ \\
\hline \multirow{7}{*}{$\begin{array}{l}\stackrel{8}{0} \\
\text { N } \\
\text { ज्ञ }\end{array}$} & \multirow{7}{*}{$\begin{array}{l}\stackrel{\widetilde{\Xi}}{0} \\
\frac{2}{2} \\
\text { 过 }\end{array}$} & $\begin{array}{l}\text { Esgotamento de reservas fósseis } \\
\text { (carvão) }\end{array}$ & Global & Ambiente natural & Global \\
\hline & & Esgotamento de reservas minerais & Global & Capacidade de produção agrícola & Global \\
\hline & & & & Capacidade de produção de madeira & Global \\
\hline & & & & Capacidade de produção de peixe e carne & Global \\
\hline & & & & Capacidade de cátions de base & Global \\
\hline & & & & Capacidade de produção de água potável & Global \\
\hline & & & & Parcela de extinção de espécies & Suécia \\
\hline \multirow{12}{*}{ 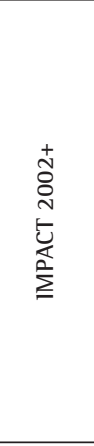 } & \multirow{12}{*}{ 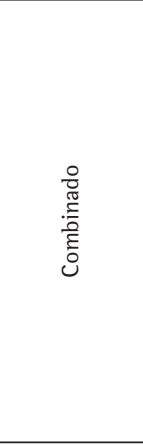 } & Toxicidade humana & Europa & Efeitos respiratórios & Europa \\
\hline & & Depleção de ozônio & Europa & Radiação ionizante & Europa \\
\hline & & Formação de ozônio fotoquímico & Europa & & \\
\hline & & Ecotoxicidade aquática & Europa & & \\
\hline & & Ecotoxicidade terrestre & Europa & & \\
\hline & & Acidificação aquática & Europa & & \\
\hline & & Eutrofização aquática & Europa & & \\
\hline & & Acidificação e eutrofização terrestre & Europa & & \\
\hline & & Ocupação do solo & Europa & & \\
\hline & & Aquecimento global & Europa & & \\
\hline & & Uso de energia não renovável & Europa & & \\
\hline & & Extração mineral & Europa & & \\
\hline \multirow{18}{*}{$\sum_{ٍ}^{\omega}$} & \multirow{18}{*}{ 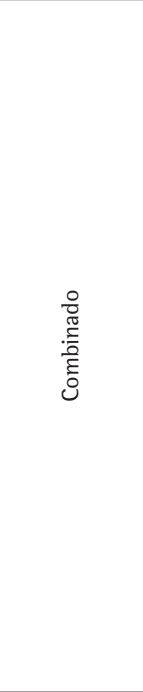 } & Aquecimento global & Global & Poluição do ar urbano & Japão \\
\hline & & Depleção da camada de ozônio & Global & Poluição do ar interior & Japão \\
\hline & & Toxicidade humana & Japão & Geração de ruídos & Japão \\
\hline & & Ecotoxicidade & Japão & Geração de resíduos & Japão \\
\hline & & Acidificação & Japão & Estresse térmico & Japão \\
\hline & & Eutrofização & Japão & Malária & Japão \\
\hline & & $\begin{array}{l}\text { Formação de oxidantes } \\
\text { fotoquímicos }\end{array}$ & Japão & $\begin{array}{l}\text { Doenças infecciosas, fome e desastres } \\
\text { naturais }\end{array}$ & Japão \\
\hline & & Uso da terra & Japão & Catarata & Japão \\
\hline & & Consumo de minerais & Japão & Câncer de pele & Japão \\
\hline & & Consumo de energia & Japão & Outro câncer & Japão \\
\hline & & Consumo de recursos bióticos & Japão & Deficiência respiratória & Japão \\
\hline & & & & Biodiversidade (terrestre) & Japão \\
\hline & & & & Biodiversidade (aquática) & Japão \\
\hline & & & & Plantas & Japão \\
\hline & & & & Bentos & Japão \\
\hline & & & & Pesca & Japão \\
\hline & & & & Colheita & Japão \\
\hline & & & & Materiais & Japão \\
\hline \multirow{10}{*}{ త్ర } & \multirow{10}{*}{ 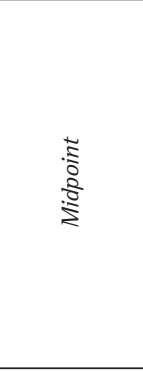 } & Mudança climática & Global & Efeitos respiratórios & Canadá \\
\hline & & Depleção de ozônio & Global & & \\
\hline & & Acidificação & Canadá & & \\
\hline & & Neblina fotoquímica $(\mathrm{smog})$ & Canadá & & \\
\hline & & Eutrofização aquática & Canadá & & \\
\hline & & Eutrofização terrestre & Canadá & & \\
\hline & & Ecotoxicidade (aquática e terrestre) & Canadá & & \\
\hline & & Toxicidade humana & Canadá & & \\
\hline & & Uso da terra & Canadá & & \\
\hline & & Destruição de recursos abióticos & Canadá & & \\
\hline \multirow{6}{*}{ 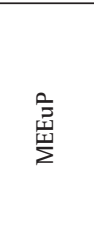 } & \multirow{6}{*}{ 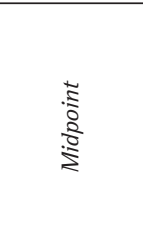 } & Consumo total de energia bruta & Europa & Resíduos sólidos perigosos & Europa \\
\hline & & Consumo de eletricidade & Europa & Resíduos não perigosos & Europa \\
\hline & & Consumo de água (processos) & Europa & $\begin{array}{l}\text { Emissão de poluentes orgânicos } \\
\text { persistentes }\end{array}$ & Europa \\
\hline & & Consumo de água para resfriamento & Europa & Emissão de compostos orgânicos voláteis & Europa \\
\hline & & Aquecimento global & Europa & Emissão de metais pesados (ar) & Europa \\
\hline & & Destruição do ozônio estratosférico & Europa & Emissão de metais pesados (água) & Europa \\
\hline
\end{tabular}


Tabela 4. Continuação...

\begin{tabular}{|c|c|c|c|c|c|}
\hline Método & $\begin{array}{l}\text { Nível de } \\
\text { avaliação de } \\
\text { impacto }\end{array}$ & Categorias de impacto tradicionais & $\begin{array}{l}\text { Abrangência de } \\
\text { aplicação }\end{array}$ & Categorias de impacto diferenciadas & $\begin{array}{l}\text { Abrangência } \\
\text { de aplicação }\end{array}$ \\
\hline \multirow{4}{*}{ 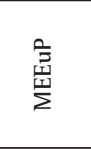 } & \multirow{4}{*}{ 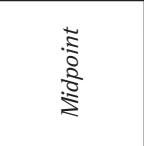 } & Acidificação & Europa & & \\
\hline & & Toxicidade humana & Europa & & \\
\hline & & Formação de partículas & Europa & & \\
\hline & & Eutrofização aquática & Europa & & \\
\hline \multirow{13}{*}{ ״ัँّ } & \multirow{13}{*}{ 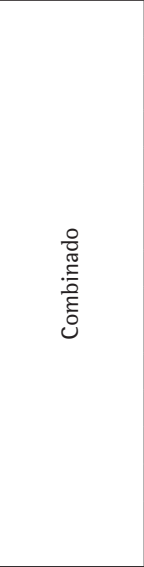 } & Mudança climática & Global & Radiação ionizante & Europa \\
\hline & & Depleção de ozônio & Global & Transformação da terra natural & Europa \\
\hline & & Acidificação terrestre & Europa & & \\
\hline & & Eutrofização (água doce e marinha) & Europa & & \\
\hline & & Toxicidade humana & Europa & & \\
\hline & & $\begin{array}{l}\text { Formação de oxidantes } \\
\text { fotoquímicos }\end{array}$ & Europa & & \\
\hline & & Formação de matéria particulada & Europa & & \\
\hline & & $\begin{array}{l}\text { Ecotoxicidade (terrestre, água doce, } \\
\text { marinha) }\end{array}$ & Europa & & \\
\hline & & Uso do solo agrícola & Europa & & \\
\hline & & Uso do solo urbano & Europa & & \\
\hline & & Esgotamento de recursos fósseis & Global & & \\
\hline & & Esgotamento de recursos minerais & Global & & \\
\hline & & $\begin{array}{l}\text { Esgotamento de recursos de água } \\
\text { doce }\end{array}$ & Global & & \\
\hline \multirow{12}{*}{ ত্ড় } & \multirow{12}{*}{ 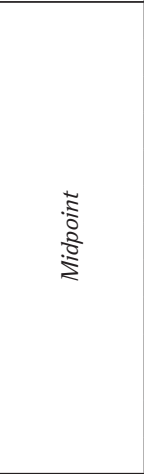 } & Depleção de ozônio & Global & & \\
\hline & & Aquecimento global & Global & & \\
\hline & & Formação de fumaça $(\mathrm{smog})$ & América do Norte & & \\
\hline & & Acidificação & América do Norte & & \\
\hline & & Eutrofização & América do Norte & & \\
\hline & & Saúde humana (carcinogênicos) & Estados Unidos & & \\
\hline & & Saúde humana (não carcinogênicos) & Estados Unidos & & \\
\hline & & Saúde humana (poluentes) & Estados Unidos & & \\
\hline & & Ecotoxicidade & Estados Unidos & & \\
\hline & & $\begin{array}{l}\text { Esgotamento de combustiveis } \\
\text { fósseis }\end{array}$ & Global & & \\
\hline & & Uso da terra & Estados Unidos & & \\
\hline & & Uso da água & - & & \\
\hline \multirow{2}{*}{ 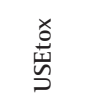 } & \multirow{2}{*}{ 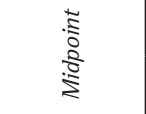 } & Toxicidade humana & Global & & \\
\hline & & Ecotoxicidade de água doce & Global & & \\
\hline \multirow{10}{*}{ 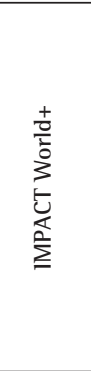 } & \multirow{10}{*}{ 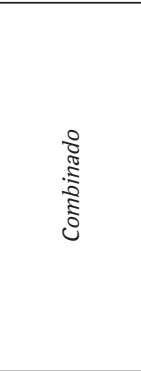 } & Toxicidade humana & Global & & \\
\hline & & Oxidação fotoquímica & Global & & \\
\hline & & Depleção da camada de ozônio & Global & & \\
\hline & & Aquecimento global & Global & & \\
\hline & & Ecotoxicidade & Global & & \\
\hline & & Acidificação & Global & & \\
\hline & & Eutrofização & Global & & \\
\hline & & Uso da água & Global & & \\
\hline & & Uso da terra & Global & & \\
\hline & & Uso de recursos & Global & & \\
\hline
\end{tabular}

Considerando-se os métodos de AICV como foram desenvolvidos originalmente, ou seja, sem a realização de adaptações, foi adotado como critério o parâmetro anteriormente descrito abrangência de aplicação. Portanto, os métodos de AICV recomendados para aplicação no Brasil são aqueles que apresentam uma abrangência classificada como global para o escopo de aplicação de suas categorias de impacto, são eles:
- CML 2002: Para as categorias de impacto depleção de recursos abióticos, uso da terra, mudança climática, depleção de ozônio estratosférico, toxicidade humana, ecotoxicidade aquática de água doce, ecotoxicidade aquática marinha, ecotoxicidade terrestre e eutrofização. Além de categorias de impactos adicionais que são abordadas dependendo dos requisitos do estudo, como perda de função de 
suporte à vida, perda de biodiversidade, ecotoxicidade em água doce (sedimentos), ecotoxicidade marinha (sedimentos), impactos da radiação ionizante, mau cheiro do ar, ruído, calor residual, acidentes, letais, não letais, depleção de recursos bióticos, dessecação e mau cheiro da água.

- EDIP 97: Para as categorias de impacto aquecimento global, depleção de ozônio, acidificação, enriquecimento de nutrientes, formação de ozônio fotoquímico, toxicidade humana, ecotoxicidade, consumo de recursos e ambiente de trabalho.

- EPS 2000: Para as categorias de impacto saúde humana, expectativa de vida, morbidade grave e sofrimento, morbidade, incômodo grave, incômodo, ambiente natural, capacidade de produção agrícola, capacidade de produção de madeira, capacidade de produção de peixe e carne, capacidade de cátions de base, capacidade de produção de água potável, consumo de recursos naturais, esgotamento de reservas de elementos, esgotamento de reservas fósseis (gás), esgotamento de reservas fósseis (petróleo), esgotamento de reservas fósseis (carvão) e esgotamento de recursos minerais.

- USEtox: Para as categorias de impacto toxicidade humana e ecotoxicidade de água doce.

- IMPACT World+: Para as categorias de impacto toxicidade humana, oxidação fotoquímica, depleção da camada de ozônio, aquecimento global, ecotoxicidade, acidificação, eutrofização, uso da água, uso da terra e uso de recursos.

Com relação às demais categorias de comparação, categoria de impacto e nível de avaliação, a opção pelo método de AICV mais adequado a ser utilizado fica a critério dos objetivos e escopo definidos no estudo de ACV pretendido.

\section{Considerações finais}

Embora a crescente adoção da ACV no desenvolvimento industrial do Brasil, verifica-se a lacuna de métodos de AICV baseados nas características regionais brasileiras.

A contribuição deste trabalho está na revisão dos principais métodos de AICV existentes, de modo a fornecer subsídios para a análise da sua aplicabilidade no Brasil.

Concluiu-se, com base nas características e particularidades dos métodos de AICV, que elas variam bastante, podendo conferir a tais métodos um grande potencial de interferência nos resultados finais da AICV e, consequentemente, na Gestão do Ciclo de Vida do produto.

Vale ressaltar que foram consideradas apenas as definições e classificações encontradas nos manuais e artigos científicos referentes a esses métodos. Um método de AlCV é composto por uma série de modelos de caracterização utilizados para avaliar cada uma de suas categorias de impacto. Desse modo, este trabalho destaca a importância de se incentivar a análise dos parâmetros e procedimentos de cálculos utilizados por cada modelo para as várias categorias de impacto existentes. Acredita-se que dessa forma seja possível realizar-se uma comparação efetiva entre os métodos de AICV, além da verificação de se os modelos e seus fatores de caracterização são realmente capazes de representar e avaliar os potenciais impactos ambientais em diferentes regiões do mundo.

\section{Referências}

Ahbe, S., Braunschweig, A., \& Müller-Wenk, R. (1990). Methodology for ecobalances based on ecological optimization. Bern: Buwal (Safel). (Environment Series, 133).

Associação Brasileira de Normas Técnicas - ABNT. (2009a). NBR ISO 14040: Gestão Ambiental - Avaliação do Ciclo de Vida - Princípios e Estrutura. Rio de Janeiro.

Associação Brasileira de Normas Técnicas - ABNT. (2009b). NBR ISO 14044: Gestão Ambiental - Avaliação do Ciclo de Vida - Requisitos e Orientações. Rio de Janeiro.

Bare, J. C. (2002). Developing a Consistent Decision-Making framework by Using the U.S. EPA's TRACI. Cincinnati: Environmental Protection Agency. Recuperado em 27 de junho de 2013, de http://www.epa.gov/ORD/NRMRL/ std/sab/traci/ aiche2002paper.pdf

Bare, J. C., Norris, G. A., Pennington, D. W. \& McKone, T. E. (2003). TRACl: The Tool for the Reduction and Assessment of Chemical and Other Environmental Impacts. Journal of Industrial Ecology, 6(3), 49-78.

Brand, G., Braunschweig, A., Scheidegger, A., \& Schwank, 0. (1998). Weighting in ecobalances with the ecoscarcity method: ecofactors 1997. Bern: Buwal (Safel). (Environment Series, 297).

Brasil, Ministério do Desenvolvimento, Indústria e Comércio Exterior, Conselho Nacional de Metrologia, Normalização e Qualidade Industrial. Dispõe sobre a Aprovação do Programa Brasileiro de Avaliação do Ciclo de Vida e dá outras providências (Resolução $\mathrm{n}^{\circ}$ 04, de 15 de dezembro de 2010). Recuperado em 27 de junho de 2013, de http:// www.inmetro.gov.br/ legislacao/resc/pdf/RESC000236.pdf.

Finnveden, G., Hauschild, M. Z., Ekvall, T., Guinée, J., Heijungs, R., Hellweg, S., Koehler, A., Pennington, D., \& Suh, S. (2009). Recent developments in Life Cycle Assessment. Journal of Environmental Management, 91, 1-21. PMid:19716647. http://dx.doi. org/10.1016/j.jenvman.2009.06.018

Frischknecht, R., Steiner, R., Arthur, B., Norbert, E., \& Gabi, H. (2006). Swiss Ecological Scarcity Method: the new version 2006. In Proceedings of the 7th International Conference on EcoBalance, Tsukuba, Japan.

Frischknecht, R., Steiner, R., \& Jungbluth, N. (2009). The Ecological Scarcity Method - Eco-Factors 2006: a method for impact assessment in LCA. Bern: Federal Office for the Environment. (Environmental studies, 906).

Goedkoop, M., Heijungs, R., Huijbregts, M., Schryver, A., Struijs, J., \& van Zelm, R. (2009). ReCiPe 2008: a life cycle 
impact assessment method which comprises harmonized category indicators at the midpoint and the endpoint level. Ministerie van Volkshuisvesting. (Report, 1).

Guinée, J. B. (2002). Handbook on Life Cycle Assessment: operational guide to the ISO Standards. Kluwer Academic Publishers.

Hauschild, M. Z., Huijbregts, M., Jolliet, O., Macleod, M., Margni, M., van de Meent, D., Rosenbaum, R. K., \& McKone, T. E. (2008). Building a model based on scientific consensus for life cycle impact assessment of chemicals: the search for harmony and parsimony. Environmental Science \& Technology, 42(19), 70327037. http://dx.doi.org/10.1021/es703145t

Hauschild, M. Z., Goedkoop, M., Guinée, J., Heijungs, R., Huijbregts, M., Jolliet, O., Margni, M., Schryver, A., Humbert, S., Laurent, A, Sala, S., Pant, R. (2012). ldentifying best existing practice for characterization modeling in life cycle impact assessment. The International Journal of Life Cycle Assessment, 18(3), 683-697.

Hauschild, M., \& Potting, J. (2005). Spatial differentiation in life cycle impact assessment: the EDIP2003 methodology. Copenhagen: Danish Ministry of the Environment. (Environmental News, 80).

Hauschild, M. Z., \& Wenzel, H. (1998). Environmental assessment of products (Vol. 2). United Kingdom: Chapman \& Hall, Hingham: Kluwer Academic Publishers.

Huijbregts, M., Hauschild, M., Jolliet, O., Margni, M., McKone, T., Rosenbaum, R. K., \& van de Meent, D. (2010). USEtoxTM User manual.

IMPACT World+. What is IMPACT World+?. (2012). Recuperado em 27 de junho de 2013, de http://www. impactworldplus.org/en/presentation. php

Itsubo, N., Sakagami, M., Washida, T., Kokubu, K., \& Inaba, A. (2004). Weighting Across Safeguard Subjects for LCIA through the Application of Conjoint Analysis. The International Journal of Life Cycle Assessment, 9(3), 196205.

Itsubo, N., \& Inaba, A. (2003). A new LCIA method: LIME has been completed. The International Journal of Life Cycle Assessment, 8(5), 305-305.

Joint Research Centre - JRC. (2010). Analysis of existing environmental impact assessment methodologies for use in life cycle assessment: background document. (ILCD Handbook).

Joint Research Centre - JRC. (2011). Recommendations based on existing environmental impact assessment models and factors for life cycle assessment in European context. (ILCD Handbook).

Jolliet, O., Margni, M., Charles, R., Humbert, S., Payet, J., Rebitzer, G., \& Rosenbaum, R. (2003). IMPACT 2002+: a new life cycle impact assessment methodology. The International Journal of Life Cycle Assessment, 8(6), 324330. http://dx.doi.org/10.1007/BF02978505
Kemna, R.., van Elburg M., Li, W., \& van Holstekjin, R. (2005). MEEUP: the methodology Report. Brussels: European Commission. (Final version).

Klöpffer, W. (2006). The role of SETAC in the development of LCA. International Journal of Life Cycle Assessment, 11, 116-122. http://dx.doi.org/10.1007/ s11367-008-0038-4

Ministry of Housing, Spatial Planning and the Environment. (2000). Eco-indicator 99 manual for designers: a damage oriented method for Life Cycle Impact Assessment.

Organização das Nações Unidas - ONU. (2012). A ONU e o meio ambiente. Recuperado em 27 de junho de 2013, de http://www.onu.org.br/ a-onu-em-acao/a-onu-e-omeio-ambiente/

Rosenbaum, R. K., Bachmann, T. M., Gold, L. S., Huijbregts, M. A. J., Jolliet, O., Juraske, R., Koehler, A., Larsen, H. F., MacLeod, M., Margni, M., McKone, T. E., Payet, J., Schuhmacher, M., van de Meent, D., \& Hauschild, M. Z. (2008). USEtox the UNEP-SETAC toxicity model: recommended characterisation factors for human toxicity and freshwater ecotoxicity in life cycle impact assessment. The International Journal of Life Cycle Assessment, 13(7), 532-546.

Schryver, A. M., Brakkee, K. W., Goedkoop, M. J., \& Huijbregts, A. J. (2009). Characterization factors for global warming in life cycle assessment based on damages to humans and ecosystems. Environmental Science and Technology, 43(6), 1689-1695. http:// dx.doi.org/10.1065/lca2005.12.242

Steen, B. (1999a). A systematic approach to environmental priority strategies in product development (EPS) (Version 2000). Gothenburg: Chalmers University of Technology. (CPM report 1999:4).

Steen, B. (1999b). A systematic approach to environmental priority strategies in product development (EPS) (Version 2000). Gothenburg: Chalmers University of Technology. (CPM report 1999:5).

Toffoletto, L., Bulle, C., Godin, J., Reid, C., \& Deschênes, L. (2007). LUCAS: a new LClA method used for a canadian-specific context. The International Journal of Life Cycle Assessment, 12(2), 93-102. http://dx.doi. org/10.1007/978-1-4615-6367-9

United Nations Environment Programme - UNEP. (2007). Life cycle management: a business guide to sustainability. Recuperado em 27 de junho de 2013, de http://www. unep.org/pdf/ dtie/DT10889PA.pdf

United Nations Environment Programme - UNEP. (2010). Life Cycle Impact Assessment Programme. Life Cycle Initiative. Recuperado em 27 de junho de 2013, de http://lcinitiative. unep.fr/sites/ lcinit/default.asp?site=lcinitctpage id=67F5A66D-9EB8- 4E75-B663-297B7FD626B6

Wenzel, H., Hauschild, M. Z., \& Alting, L. (1997). Environmental assessment of products (vol. 1). United Kingdom: Chapman \& Hall, Hingham: Kluwer Academic Publishers. http://dx.doi.org/10.1007/978-1-4615-6367-9 


\section{Life Cycle Impact Assessment: a review of the main methods} Abstract

Life Cycle Impact Assessment (LCIA) is the third phase of life Cycle Assessment (LCA). It involves assessing the environmental significance of inventory results by using characterization models and factors contained in LCIA methods. This paper identifies the main LCIA methods and describes their characteristics. Through a literature review, 13 LCIA methods were identified. Most of them were developed in Europe and have been used throughout the world, including Brazil. Among these methods have been identified those with a global scope of application, being recommended for the use in Brazil. Each LClA method evaluates different impact categories by means of a number of different characterization models, so it was concluded that there is a need to analyze the calculation procedures used by each model to provide support for the application of these methods and models in different regions of the world. Keywords

Life Cycle Impact Assessment. Life Cycle Impact Assessment Methods. 